\title{
Active paraoxonase 1 is synthesised throughout the internal boar genital organs.
}

Isabel Barranco, Cristina Perez-Patiño, Asta Tvarijonaviciute, Inmaculada Parrilla, Alejandro Vicente-Carrillo, Manuel Alvarez-Rodriguez, J ose J Ceron, Emilio A Martinez, Heriberto Rodriguez-Martinez and J ordi Roca

The self-archived postprint version of this journal article is available at Linköping University Institutional Repository (DiVA):

http:// urn.kb.se/ resolve?urn=urn:nbn:se:liu:diva- 140727

N.B.: When citing this work, cite the original publication.

Barranco, I., Perez-Patiño, C., Tvarijonaviciute, A., Parrilla, I., Vicente-Carrillo, A., Alvarez-Rodriguez, M., Ceron, J . J, Martinez, E. A, Rodriguez-Martinez, H., Roca, J., (2017), Active paraoxonase 1 is synthesised throughout the internal boar genital organs., Reproduction, 154(3), 237-243.

https:// doi.org/ 10.1530/REP-17-0300

Original publication available at:

https:// doi.org/ 10.1530/REP-17-0300

Copyright: BioScientifica

http:// www.bioscientifica.com/ 


\section{Active paraoxonase 1 is synthesised throughout the internal boar genital tract}

Isabel Barranco ${ }^{1}$, Cristina Perez-Patiño ${ }^{1}$, Asta Tvarijonaviciute $^{1}$, Inmaculada Parrilla ${ }^{1}$, Alejandro Vicente-Carrillo ${ }^{2}$, Manuel Alvarez-Rodriguez ${ }^{2}$, Jose J. Ceron ${ }^{1}$, Emilio A. Martinez $^{1}$, Heriberto Rodriguez-Martinez ${ }^{2, *}$, Jordi Roca ${ }^{1, *}$

${ }^{1}$ Department of Medicine and Animal Surgery, Faculty of Veterinary Science, University of Murcia, Spain and ${ }^{2}$ Department of Clinical and Experimental Medicine (IKE), University of Linköping, Sweden.

Correspondence should be addressed to J Roca; E-mail: roca@um.es

*Senior authors

Short title: Paraoxonase 1 in boar genital tract 


\section{Abstract}

The paraoxonase type 1 (PON1) is an enzyme with antioxidant properties recently identified in the seminal plasma (SP) of several species, including the porcine. The aims of the present study were to (1) describe the inmunohistochemical localization of PON1 in the genital tract of fertile boars and (2) evaluate the relationship among PON1 activity and high-density lipoprotein cholesterol (HDL-C) concentration in fluids of the boar internal genital tract. Immunohistochemical analysis demonstrated that PON1 was present in testis (specifically in Leydig cells, blood vessels, spermatogonia and elongated spermatids), epididymis (specifically in the cytoplasm of the principal epithelial cells, luminal secretion and in the surrounding smooth muscle) and the lining epithelia of the accessory sexual glands (cytoplasmic location in the prostate and membranous in the seminal vesicle and bulbourethral glands). The western blotting analysis confirmed the presence of PON1 in all organs of boar genital tract, showing in all of them a band of $51 \mathrm{kDa}$, and an extra band of $45 \mathrm{kDa}$ only in seminal vesicles. PON1 showed higher activity levels in epididymal fluid than in SP of the entire ejaculate or of specific ejaculate portions. A highly positive relationship between PON1 activity and HDL-C concentration was found in all genital fluids. In sum, all boar genital organs contributing to sperm-accompanying fluid/s were able to express PON1, whose activity in these genital fluids is highly dependent on the variable HDL-C concentration present. 


\section{Introduction}

Paraoxonase type 1 (PON1) is a high-density lipoprotein cholesterol (HDL-C)-associated enzyme present in blood that prevents the oxidation of low-density lipoprotein-cholesterol (LDL-C) (Mackness et al. 1996). PON1 has acquired scientific notoriety in recent years welcoming its protective role in preventing many human diseases involving oxidative stress and associated with atherosclerosis, including cardiovascular and neurological disorders, diabetes, cancer and aging (recently revised by Mahrooz 2016). Recently, PON1 has been identified in seminal plasma (SP) of men (Verit et al. 2009; Marsillach et al. 2011) and of some livestock males, such as rooster (Khan et al. 2012), boar (Barranco et al. 2015a) and bull (Dedeoglu et al. 2014).

Currently, little is known of PON1 in the male genital tract, particularly in relation to the site of synthesis. Only two studies, one in mice (Marsillach et al. 2008) and other in men (Marsillach et al. 2011), have partially addressed this issue, both focused exclusively to the testis, showing that Leydig cells are capable of synthesizing PON1. However, the Leydig cells seem not to be the only source of SP-PON1, particularly in sires of livestock species (bull, boar) where SP-PON1 activity is substantially higher than in men. The boar ejaculate is sequentially expelled in two main fractions. The first constitutes the sperm-rich fraction (SRF), where the majority of spermatozoa are bathing in fluids mainly from cauda epididymal (emitted with the spermatozoa) and prostate. The second one is called post-SRF fraction and is dominated by secretions from seminal vesicles (Rodriguez-Martinez et al. 2011). PON1 is present in SP of both ejaculate fractions (Barranco et al. 2015b), which would indicate that the enzyme could be synthesized throughout the entire internal genital tract, 
including the accessory sex glands. To clarify this issue is one of the aims of the present study.

A high secretion of PON1 in the reproductive tissues does not seem to necessarily entail a high activity of the enzyme in the surrounding fluids, as no relationship between PON1 concentration and enzyme activity was found in boar SP samples (Barranco et al. 2015a). The PON1 activity seems to be linked to the presence of HDL-C, at least in human blood serum (Granér et al. 2006). So far, the association between and HDL-C and PON1 activity has not been evidenced in genital fluids. In boar SP, the PON1 activity clearly differs among specific fractions of the ejaculate, the SRF showing the largest enzyme activity (Barranco et al. 2015b). The present study also aims to evaluate whether differences in PON1 activity among genital fluids could be associated to differences in HDL-C concentration. To achieve these goals, reproductive tissues and fluids were collected from mature, healthy and fertile boars slaughtered for genetic replacement after serving as sires for artificial insemination (AI) commercial breeding.

\section{Material and methods}

\section{Reagents and media}

All chemicals used in the experiments were of analytical grade and, unless otherwise stated, purchased from Sigma-Aldrich (St. Louis, MO, USA). The primary rabbit primary polyclonal antibody against PON1 (ab53193) and its blocking peptide peptide (ab218259) were purchased from Abcam (Cambridge, UK). The basic medium used for reactive dilutions was EDTA-free phosphate buffered saline (PBS: $139 \mathrm{mM} \mathrm{NaCl}, 2.7 \mathrm{mM} \mathrm{KCl}, 1.5 \mathrm{mM}$ 
$\mathrm{KH}_{2} \mathrm{PO}_{4}, 8.1 \mathrm{mM} \mathrm{Na} \mathrm{HPO}_{4} \cdot 7 \mathrm{H}_{2} \mathrm{O}$; with $0.058 \mathrm{~g} / \mathrm{L}$ penicillin $\mathrm{G}$ and $0.05 \mathrm{~g} / \mathrm{L}$ streptomycin sulphate; pH 6.8 and 280-300 mOsmol/kg)

\section{Animals and samples}

The handling of the animals and tissues and all procedures described below were performed according to international guidelines (Directive 2010/63/EU) and approved by the Bioethics Committee of Murcia University (research code: 639/2012).

Ejaculates, epididymal cauda luminal fluid and internal reproductive tissues were obtained from healthy and sexually mature boars (aged 18 to 36 months) of different breeds and crossbreeds belonging to AI centre (AIM Iberica, Calasparra, Murcia, Spain). Boars were housed in individual pens in an environmentally controlled $\left(15-25^{\circ} \mathrm{C}\right)$ building with windows, such that they were exposed to $16 \mathrm{~h}$ of natural daylight and supplementary light per day. The boars were provided ad libitum access to water, and were fed commercial diets according to nutritional requirements for adult boars (Chiba 2009).

Ejaculates $(n=30)$ were collected from 10 AI-boars (3 ejaculates per boar) using the gloved-hand method. The ejaculates were collected in 3 separate portions, the first $10 \mathrm{~mL}$ of the SRF (sperm-peak portion), the rest of the SRF and the post-SRF. A proportion of each portion was mixed to simulate a re-composed entire ejaculate, albeit of lower volume. All ejaculates fulfilled the standards of quantity and sperm quality thresholds for the preparation

of semen AI-doses: more than $200 \times 10^{6}$ spermatozoa/mL, 70\% motile spermatozoa, and $75 \%$ of morphologically normal cells. Semen samples of each of the three portions and the entire ejaculate were processed for SP-collection as indicated below. 
Boars were retired, while still healthy, fertile and reproductive fit, from the AI-centre for genetic replacement reasons, and sent to a slaughterhouse (La Mata de los Olmos, Teruel, Spain). Once slaughtered, genital tracts were collected and then epididymal cauda lumen contents and tissues samples obtained. The content of the cauda epididymal lumen was collected following the procedure described by Alkmin et al. (2014) with slight modifications. The epididymides were removed and dissected avoiding blood contamination. Cauda epididymal lumen content was retrogradely collected from the vas deferens by injecting an air segment until all the luminal fluid was flushed out. The harvested cauda epididymal lumen content from the two epididymis of each boar were mixed and processed for epididymal fluid collection as indicated below.

Tissues samples $(1 \mathrm{~cm} \times 1 \mathrm{~cm}$ and $1 \mathrm{~mm}$ thick) of the internal genital organs were collected; specifically from medial testis, the caput, corpus and cauda segments of the ductus epididymides, and mid-areas of the prostate, the seminal vesicle and the bulbourethral gland. Samples were immediately frozen by plunging in liquid nitrogen (for Western Blot [WB] analysis) or immersion-fixed in $4 \%$ phosphate-buffered formalin (for immunohistochemical analysis).

\section{Processing and storage of seminal plasma and epididymal fluid}

Cell-free SP and epididymal fluids were obtained immediately after ejaculate and epididymis collection through double centrifugation (1,500 xg for $10 \mathrm{~min}$ at room temperature, Rotofix 32A, Hettich Centrifuge UK, Newport Pagnell, Buckinghamshire, England, UK). The second supernatant was harvested and examined by microscopy (Eclipse E400, Nikon, Tokyo, Japan) to ensure it was sperm-free. Then, the samples were stored in cryotubes and sent in 
insulated containers with dry ice to the Andrology Laboratory at the Veterinary Teaching Hospital of the University of Murcia. At the laboratory, the SP-samples were stored at $-80^{\circ} \mathrm{C}$ (Ultra Low Freezer, Haier Inc., Qingdao, China) until analysis. For analyses, the samples were thawed at room temperature.

\section{Immunohistochemical examination}

Sections of paraffin-embedded tissue samples ( $4 \mu \mathrm{m}$ thickness mounted on Superfrost Plus slides; Thermo Scientific, Gothenburg, Sweden) were immunohistochemically stained using an avidin-biotin complex technique (Vector Laboratories, Burlingame, CA, USA). The sections were deparaffinized by washing three times with Histo-Clear (Histolab, Gothenburg, Sweden), progressively rehydrated from 100 to 50\% ethanol, and placed in distilled water. All washing between incubations was performed with PBS-Tween (0.01\%, PBST), with a final wash in distilled water. Antigen retrieval was performed in $10 \mathrm{mM}$ Tris-1 mM EDTA (pH 9.5) and microwave exposure for 20 min (Svensson-Arvelund et al. 2015). Sections were incubated overnight at $4{ }^{\circ} \mathrm{C}$ with the rabbit primary polyclonal antibody against PON1 (ab53193, Abcam), diluted 1/100 in PBS with 1\% BSA containing 3\% normal goat serum blocking solution (Dako, Stockholm, Sweden) and 1\% Triton X-100. As negative control, human skeletal muscle and pig liver samples were pre-incubated with the blocking PON1 peptide (ab218259, Abcam, diluted 1/20 in PBS with 1\% BSA) upon which the primary antibody was raised upon, while samples from human skeletal muscle and pig liver were used as positive controls. After washing, sections were incubated with a polyclonal goat anti-rabbit secondary antibody conjugated with biotin (Dako, Stockholm, Sweden), diluted 1/300 in PBS

containing 3\% normal goat serum blocking solution and 1\% Triton X-100 for 30 min. 
Sections were washed, and endogenous peroxidase activity was blocked by incubating the sections with $3 \% \mathrm{H}_{2} \mathrm{O}_{2}$ for $20 \mathrm{~min}$. The immunostaining was developed using the VECTASTAIN Elite ABC kit and ImmPACT DAB Peroxidase (HRP) Substrate (Vector Labs, Burlingame, USA). The immunostained slides were mounted with ImmunoHistoMount prior visualization and photography, which were performed using an upright Olympus BX51 light microscope, equipped with phase contrast optics and a XC30 camera, and the CellSens Olympus imaging software (Olympus, Münster, Germany). The immunostaining at slide level was ranked by three independent observers for determining eventual changes in distribution or subjective intensity among the boars explored ( $\mathrm{n}=6)$. A simple ranking system (0: no staining, +-+++ various degrees of immune stating intensity) was used and averaged between observers.

\section{Western Blotting (WB)}

Tissue samples were thawed at room temperature and proteins were extracted by initially incubating them at $4{ }^{\circ} \mathrm{C}$ for 40 min with RIPA buffer and a tablet of protease inhibitors (Complete Mini EDTA-free; Roche, Mannhein, Germany) for each $10 \mathrm{~mL}$ of homogenization solution. After this incubation, the samples were homogenized with potter homogenizer. Once the proteins were extracted, the samples were centrifuged 13,000 xg 10 min and the supernatants containing the proteins collected. Protein quantification was done using the BCA method (Pierce, Rockfordd, USA). The protein suspension was denatured in loading buffer by heating to $95^{\circ} \mathrm{C}$ for $5 \mathrm{~min}$. Twenty $\mu \mathrm{g}$ of the protein suspension was loaded per lane into a Mini-PROTEAN TGX precast gels-12 \% Bis-Tris SDS-PAGE gel (Bio-Rad Laboratories, USA). Electrophoresis was run at $180 \mathrm{~V}$ for $45 \mathrm{~min}$ and performed with two 
marker standards: Precision Plus Protein Dual Color Standarts and SDS-PAGE Molecular Weight Standart (Bio-Rad Laboratoires, California, USA). The proteins were transferred to Immobilon-P membranes (Millipore, Bedford, USA) by semidry electrophoretic transfer at $240 \mathrm{~mA}$ for $60 \mathrm{~min}$. Once the proteins were transferred to the membrane, blocking was done overnight with $5 \% \mathrm{BSA}$ in PBST at $4^{\circ} \mathrm{C}$. Following 3 washes of $5 \mathrm{~min}$ in PBST the membrane was incubated overnight at $4{ }^{\circ} \mathrm{C}$ with a dilution $1 / 1000$ of the primary antibody (rabbit polyclonal anti-PON1) in PBST with 1\% BSA. Next day, the membrane was washed three times in PBST and incubated for 75 min with a dilution 1/5000 of the secondary antibody (Goat anti-rabbit IgG Biotinylated, Millipore California) in PBST with 1\% BSA followed by extensive washing in PBST. Subsequently, the membranes were incubated with HRP-streptravidin (Dako) diluted 1/5000 in PBST whit 1\% BSA, for 45 min. The inmunoreactive bands were located whit Clarity Western ECL Substrate (Bio-Rad Laboratories). The images of the blottings were obtained using the ImageQuant LAS 500 (Healthcare Life Sciencies, USA).

\section{Measurement of PON1 activity}

The PON1 enzymatic activity was assessed in vitro, measuring the hydrolysis of pnitrophenyl acetate to p-nitrophenol in an automated analyzer (Olympus AU600 Automatic Chemistry Analyzer, Olympus Europe GmbH, Hamburg, Germany) as described by Barranco et al. (2015a). The p-nitrophenyl acetate is the recommended substrate for measuring PON1 enzymatic activity in body fluids (Ceron et al. 2014). The samples (epididymal fluid and SP) were treated before analysis with Acetazolamide $(0.5 \mathrm{mM})$ and Di-isopropyl fluorophosphates $(0.5 \mathrm{mM})$ to ensure that there were no contaminating enzymes 
other than PON1 capable of hydrolysing p-nitrophenyl acetate. This assay had intra- and inter-assay coefficient variations $<10 \%$, high linearity under serial dilutions and a limit of detection of $0.01 \mathrm{IU} / \mathrm{mL}$. PON1 activity of each sample was measured in duplicate and results were expressed as IU/mL.

\section{Measurement of HDL-C concentration}

The HDL-C concentration was quantified using a commercial kit (HDL-C OSR6187, Beckman Coulter, Brea, CA, USA) and following the manufacturer instructions. Briefly, first the non-HDL-lipoproteins (LDL-C, VLDL-C and chylomicrons) present in the samples were blocked by an antibody (anti human- $\beta$-lipoprotein) and then the unbound HDL-C reacted with cholesterol esterase, cholesterol oxidase and a chromogen system giving a blue colour complex that was measured bichromatically at 600/700 nm using an automatic chemistry analyzer (Olympus AU 600). The HDL-C concentration of each sample was measured in duplicate and results were expressed as $\mathrm{mg} / \mathrm{dL}$.

\section{Statistical analysis}

Data of PON1 activity and HDL-C concentration were statistical analyses using SPSS, version 19 (SPSS, Chicago, IL, USA). The residual data of each variable was evaluated using the Kolmogorov-Smirnov test to check the assumption of normality. The nonparametric Kruskal-Wallis test was used to evaluate the differences among samples (epididymal fluid and SP-samples of entire ejaculate and different ejaculate portions). When appropriate, the data from the different samples were compared using the non-parametric Mann-Whitney U 
test. The relationship between PON1 activity and HDL-C concentration was evaluated using the Spearman Rho correlation test. Statistical significance was defined as $\mathrm{P}<0.05$.

\section{Results}

\section{Expression of PON1 in boar genital tract}

The PON1 was hereby immunolocalized in all boar genital organs. Negative controls (human skeletal muscle and pig liver samples pre-incubated with the peptide upon which the primary antibody was raised) appeared unstained (see representative section in Fig. 1A and C) while the positive control (human skeletal muscle and pig liver) appeared -as expectedimmunostained (Fig. 1B and D). PON1 was localized in the ductus epididymides, with a noticeably more evident immunostaining in the caput and corpus regions, mainly on the principal cells and in the surrounding smooth muscle (Fig. 2A-C). The immunostaining was intracytoplasmic, but yielded the basal and apical membranes markedly stained. The lumen of the epididymis, containing epididymal secretion where spermatozoa appeared embedded in, was also positively stained, a picture conspicuously similar to the lumen of the prostate and the other accessory glands (Fig. 2E-G). The boar testis showed a consistent marked staining of the interstitium, predominantly on the Leydig cells and the surrounding blood vessels. The seminiferous tubules only presented a faible immunostaining of the spermatogonia and of the elongated spermatids/apical area of the Sertoli cells (Fig. 2D). The prostatic secretory cells showed a predominantly intracytoplasmic staining, leaving the nuclear area negative (similar to what could be seen in all other sections) with a faible, scattered staining in the lamina propria (Fig. 2E). The immunolocalization pattern changed from cytoplasmic to a more membranous type in the seminal vesicles (Fig. 2F), where 
particularly the basal membrane was strongly stained while the cytoplasm appeared stained at the apical region, towards the lumen of the tubule-alveolar glands. A consistently membranous localization appeared in the basal and lateral epithelial membranes of the bulbourethral tubular glands (Fig. 2G). There were no obvious differences in staining neither distribution nor subjective intensity (++) among boars.

The WB confirmed the presence of PON1 in testis, epididymis and all accessory glands. PON1 was detected in all reproductive organs as one bands of approximately $51 \mathrm{kDa}$

(Fig. 3). In addition, the seminal vesicles showed an additional band of approximately 45 kDa (Fig. 3).

\section{Relationship between PON1 activity and HDL-C concentration in boar genitals}

The PON1 activity varied significantly $(\mathrm{P}<0.01)$ among the samples. The epididymal fluid showed the highest levels $(1.14 \pm 0.06 \mathrm{IU} / \mathrm{mL}$, ranging from 0.73 to 1.83$)$, whereas the SP from post-SRF showed the lowest activity levels $(0.08 \pm 0.01 \mathrm{IU} / \mathrm{mL}$, ranging from 0.02 to 0.15) (Fig. 4A). The HDL-C concentration also differed significantly $(\mathrm{P}<0.001)$ among the samples, showing the same pattern than PON1 activity. The epididymal fluid showed the highest concentrations ( $3.55 \pm 0.10 \mathrm{mg} / \mathrm{dL}$, ranging from 2.49 to 4.46 ), whereas the SP from post-SRF showed the lowest concentrations $(0.09 \pm 0.02 \mathrm{mg} / \mathrm{dL}$, ranging from 0 to 0.28$)$ (Fig. 4B). A positive correlation was found between PON1 activity and HDL-C concentration ( $\mathrm{r}=$ 0.89; $\mathrm{P}<0.001)$, irrespective of the sample.

\section{Discussion}


In this study, the immunohistochemical analyses demonstrated, for the first time in mammalian species, that all organs of the internal genital tract of the pig are able to express the esterase protein aryldialkylphosphatase PON1. The immunolabelling followed a clear pattern, basically similar among the males explored; PON1 was apparently present in association with blood vessels, but also in relation to spermatozoa, from elongated spermatids to epididymal sperm. The enzyme was conspicuously localized in the epididymal epithelium (principal cells) as well as in the secretory epithelium of the accessory sexual glands. In the later, the localization differed, from membrane-bound in the seminal vesicles and bulbourethral glands, to a more conspicuous cytoplasmic location in the prostate, similarly to what was evident in the epididymis. To the best of our knowledge, presence of PON1 was only previously identified in testicular tissue of men, specifically in the cytoplasm of spermatogonia (Marsillach et al. 2011) and in mice testes, where the location included not only the germ cells but also the Leydig cells (Marsillach et al. 2008). Our present results indicate a similar presence of PON1 in Leydig cells, elongated spermatids and spermatogonia, suggesting a role of the enzyme during spermatogenesis and the hormonal production of cholesterol-derived hormones, such as testosterone. On the other hand, this present study is novel in the sense that it seems to be the first description of PON1 in the epididymis and accessory sex glands (e.g. prostate, seminal vesicle and bulbourethral glands) all involved in the production of the SP, the basic vehicle for ejaculated spermatozoa. Since studies in other species have not involved the accessory sexual glands, it is not possible to discuss eventual inter-species differences in the localization of this enzyme in the male genital tract. This is unfortunate in the light of differences between species for the localization of another antioxidant enzyme; the superoxide dismutase (Oberley et al. 1990; Nonogaki et al. 1992). While Oberley et al. (1990) demonstrated that superoxide dismutase was not 
present in spermatogonia from hamster testicular tissue; Nonogaki et al. (1992) showed that this enzyme was present in the cytoplasm and nucleus of human spermatogoniae. In this sense, the presence of another SP antioxidant, glutathione peroxidase 5, has also been described in all internal organs of boar, including the accessory sexual glands (Barranco et al. 2016). Overall, these findings indicate the accessory glands produce antioxidant enzymes found thereafter in the SP, at least in the boar. Regarding the current findings for the PON1, its wide distribution in the gonad and the sperm maturation site along the epididymal duct would indicate that this enzyme could have a relevant role in the functional development of germ cells and even on their survival during sperm maturation, as part of a defence mechanism against oxidative stress that could jeopardize a normal spermatogenesis and the preservation of membrane and chromatin intactness during the lengthy epididymal sperm transport. In this sense, Barranco et al. (2015b) suggested SP-PON1 main role is to attenuate the intracellular generation of reactive oxygen species in boar spermatozoa.

The WB analysis confirmed the presence of PON1 in all organs of boar genital tract, showing a band of $51 \mathrm{kDa}$; a higher molecular weight than that found by Gan et al. (1991) and Connelly et al. (2008) in human serum where it was placed in a band between 40 and 45 kDa. In contrast, PON1 in a band of $66 \mathrm{kDa}$ was found in bull semen (Dedeoglu et al. 2014). The differences in molecular weight could be related to differences in glycosylation, as PON1 molecular weight decreases when deglycosylated (Riedmaier et al. 2011). In this way, the above results would also indicate that the enzyme in semen is more glycosylated than in serum or, alternatively, that boar and bull PON1 is more glycosylated than human PON1, irrespective of the place of synthesis. Brushia et al. (2001) demonstrated that PON1 decreases in activity when it was deglycosylated, which would support the above second statement as the activity of PON1 in the genital tract of boar and bull is higher than in that of man 
(Marsillach et al. 2011). Surprisingly, our results of WB showed an extra band of $45 \mathrm{kDa}$ in the extracted protein of seminal vesicles, which would be associated with a less glycosylated form of PON1 and thereby with a less activity. This finding could explain in part the differences in activity of SP-PON1 among the boar ejaculate portions, as it is lower in postSRF portion whose SP is mainly built from the seminal vesicle (Einarsson 1971, RodriguezMartinez et al. 2009).

The PON1 activity differed among the fluids of boar genital tract, showing the epididymal fluid larger activity than SP of ejaculate (entire ejaculate or specific ejaculate portions). Among the ejaculate portions, the highest activity was in the SP of the first $10 \mathrm{~mL}$ of SRF and the lowest in the SP of the post-SRF. These differences were in part expected given the immunohistochemical and WB results. However, the extent of the differences exceeds that expected from the immunohistochemical and WB results. Note the larger activity in the epididymal fluid, 3-6 times higher than that in the entire ejaculate or in its specific portions. It is particularly relevant the differences in activity between epididymal fluid and SP of the $10 \mathrm{ml}$ of SRF, which comes mainly from epididymal fluid. Overall, these results would indicate that the synthesis of PON1 was not related with its activity and that the expression of activity would be modulated by other/s components present in the different fluids of male genital tract. HDL-C is required for PON1 activity, as HDL-C furnishes a hydrophobic environment that shields the hydrophobic N-terminal region of the enzyme stabilizing it (James \& Deakin 2004). Then, PON1 activity directly follows the amount of HDL-C, as demonstrated by Granér et al. (2006) in human blood serum. Accordingly, the results of the present study showed for first time in male genital fluids, using pig as model species, a highly significant relationship between the concentration of HDL-C and the activity of PON1. This strong relationship seems clearly to reveal that the activity of PON1 
in male genital fluids depends of the concentration of HDL-C. Experimental studies developed in different livestock species have welcomed the inclusion of cholesterol as additive in seminal extenders for improving sperm performance, suggesting that cholesterol incorporates into the sperm membranes improving their stability (revised by Mocé et al. 2010). This study would emphasize that the beneficial properties of cholesterol as additive, particularly of HDL-C, for sperm performance could also go via activation of latent PON1 present in SP.

In conclusion, the present study showed that all internal genital boar organs are able to synthetize PON1, which would mainly be in a highly glycosylated form. However, the levels of synthesis would not match those of activity in genital fluids, including seminal plasma, probably depending of the variable concentration of HDL-C present in the different genital fluid, as HDL-C is clearly required for PON1 activity.

\section{Declaration of interest}

The authors declare no conflicts of interest with regard to this study.

\section{Funding}

This experimental study was supported by MINECO (Spain) and FEDER funds (EU) (AGL2012-39903; AGL2015-69738-R), Seneca Foundation Murcia, Spain (19892/GERM15), the Swedish Research Council (VR, 521-2011-6353), the Swedish Research Council Formas (221-2011-512) and the Research Council in Southeast Sweden (FORSS, 378091/312971), Sweden. I. Barranco and C. Perez-Patiño were financially supported by MECD (Madrid, Spain) and Seneca Foundation (Murcia, Spain), respectively. 


\section{Author contribution statement}

J Roca, EA Martinez, JJ Ceron and H Rodriguez-Martinez obtained the funding to carry out the study. J Roca and H Rodriguez-Martinez conceived and directed the study. I Barranco, C Perez-Patiño, A Tvarijonaviciute, I Parrilla, A Vicente-Carrillo and M Alvarez-Rodriguez designed and performed the experiments. J Roca and H Rodriguez-Martinez analysed and interpreted the data. I Barranco and C Perez-Patiño wrote the manuscript. J Roca, EA Martinez, JJ Ceron and H Rodriguez-Martinez revised the manuscript. All authors approved the manuscript and the version to be published.

\section{Acknowledgements}

The authors are grateful to AIM Iberica (Topigs Norsvin Iberica) for supplying the boar ejaculates and organ samples and to Dr. L.M. Pastor and J. Martinez of University of Murcia for their valuable technical assistance.

\section{References}

Alkmin DV, Perez-Patiño C, Barranco I, Parrilla I, Vazquez JM, Martinez EA, Rodriguez-Martinez H \& Roca J 2014 Boar sperm cryosurvival is better after exposure to seminal plasma from selected fractions than to those from entire ejaculate. Cryobiology 69 203-10. (doi: 10.1016/j.cryobiol.2014.07.004)

Barranco I, Roca J, Tvarijonaviciute A, Rubér M, Vicente-Carrillo A, Atikuzzaman M, Ceron JJ, Martinez EA \& Rodriguez-Martinez H 2015a Measurement of activity and 
concentration of paraoxonase 1 (PON1) in seminal plasma and identification of PON2 in the sperm of boar ejaculates. Molecular Reproduction and Development 82 58-65. (doi: 10.1002/mrd.22444)

Barranco I, Tvarijonaviciute A, Perez-Patiño C, Alkmin DV, Ceron JJ, Martinez EA, Rodriguez-Martinez H \& Roca J 2015b The activity of paraoxonase type 1 (PON-1) in boar seminal plasma and its relationship with sperm quality, functionality, and in vivo fertility. Andrology 3 315-320. (doi: 10.1111/andr.309)

Barranco I, Tvarijonaviciute A, Perez-Patiño C, Vicente-Carrillo A, Parrilla I, Ceron JJ, Martinez EA, Rodriguez-Martinez H \& Roca J 2016 Glutathione Peroxidase 5 is expressed by the entire pig male genital tract and once in the seminal plasma contributes to sperm survival and in vivo fertility. PLoS One $\mathbf{1 1}$ e0162958. (doi: 10.1371/journal.pone.0162958)

Brushia RJ, Forte TM, Oda MN, La Du BN \& Bielicki JK 2001 Baculovirus-mediated expression and purification of human serum paraoxonase 1A. Journal of Lipid Research 42 951-958.

Ceron JJ, Tecles F \& Tvarijonaviciute A 2014 Serum paraoxonase 1 (PON1) measurement: an update. BMC Veterinary Research 10:74. (doi: 10.1186/1746-6148-10-74)

Chiba L 2009 Pig nutrition and feeding In Animal Nutrition Handboock, pp 285-315. Eds L Chiba. Auburn, Auburn University. 
Connelly PW, Maguire GF, Picardo CM, Teiber JF \& Draganov D 2008 Development of an immunoblot assay with infrared fluorescence to quantify paraoxonase 1 in serum and plasma. Journal of Lipid Research 49 245-50. (doi: 10.1194/jlr.D700022-JLR200)

Dedeoglu N, Arslan M \& Erzengin M 2014 Purification of Holstein Bull Semen Paraoxonase 1 (PON1) by hydrophobic interaction chromatography and investigation of its inhibition kinetics by heavy metals. Biological Trace Element Research 158 29-35. (doi: 10.1007/s12011-014-9916-8)

Einarsson S 1971 Studies on the composition of epididymal content and semen in the boar. Acta Veterinaria Scandinavica Supplementum 36 1-80.

Gan KN, Smolen A, Eckerson HW \& La Du BN 1991 Purification of human serum paraoxonase / arylesterase. Evidence for one esterase catalyzing both activities. Drug Metabolism and Disposition 19 100-106.

Granér M, James RW, Kahri J, Nieminen MS, Syvänne M \& Taskinen MR 2006 Association of paraoxonase-1 activity and concentration with angiographic severity and extent of coronary artery disease. Journal of the American College of Cardiology 472429 35. (doi: 10.1016/j.jacc.2006.01.074) 
James RW \& Deakin SP 2004 The importance of high-density lipoproteins for paraoxonase-1 secretion, stability, and activity. Free Radical Biology \& Medicine 37 19861994. (10.1016/j.freeradbiomed.2004.08.012)

Khan RU, Laudadio V \& Tufarelli V 2012 Semen traits and seminal plasma biochemical parameters in white leghorn layer breeders. Reproduction in Domestic Animals 47 190-195. (doi: 10.1111/j.1439-0531.2011.01821.x)

Mackness MI, Mackness B, Durrington PN, Connelly PW \& Hegele RA 1996 Paraoxonase: biochemistry, genetics and relationship to plasma lipoproteins. Current Opinion in Lipidology 7 69-76

Mahrooz A 2016 Pharmacological interactions of paraoxonase 1 (PON1): A HDL-bound antiatherogenic enzyme. Curr Clin Pharmacol 11. (doi: $10.2174 / 1574884711666160915153433)$

Marsillach J, Mackness B, Mackness M, Riu F, Beltran R, Joven J \& Camps J 2008 Immunohistochemical analysis of paraoxonases-1, 2, and 3 expression in normal mouse tissues. Free Radical Biology \& Medicine 45146157.

Marsillach J, Lafuente R, Checa MA, Maestre-Martinez C, Fabian E, Brassesco M, Beltran-Debon R, Aragones G, Carreras R, Pedro-Botet J et al. 2011 Paraoxonase-1 is only present in traceable amounts in seminal fluid and does not show any relationship with male subfertility. BJU International 108 566570. (doi: 10.1111/j.1464-410X.2010.09888.x) 
Mocé E, Blanch E, Tomás C \& Graham JK 2010 Use of cholesterol in sperm cryopreservation: present moment and perspectives to future. Reproduction in Domestic Animals 45 57-66. (doi: 10.1111/j.1439-0531.2010.01635.x)

Nonogaki T, Noda Y, Narimoto K, Shiotani M, Mori T, Matsuda T \& Yoshida O 1992 Localization of CuZn-superoxide dismutase in the human male genital organs. Human Reproduction 7 81-85.

Oberley TD, Oberley LW, Slattery AF, Lauchner LJ \& Elwell JH 1990 Immunohistochemical localization of antioxidant enzymes in adult Syrian hamster tissues and during kidney development. The American Journal of Pathology 137 199-214.

Riedmaier S, Klein K, Winter S, Hofmann U, Schwab M \& Zanger UM 2011 Paraoxonase (PON1 and PON3) polymorphisms: impact on liver expression and atorvastatinlactone hydrolysis. Frontiers in Pharmacology 2 41. (doi: 10.3389/fphar.2011.00041)

Rodriguez-Martinez H, Kvist U, Ernerudh J, Sanz L \& Calvete JJ 2011 Seminal plasma proteins: what role do they play? American Journal of Reproductive Immunology 66 11-22. (doi: 10.1111/j.1600-0897.2011.01033.x)

Rodriguez-Martinez H, Kvist U, Saravia F, Wallgren M, Johannisson A, Sanz L, Peña FJ, Martinez EA, Roca J, Vazquez JM et al. 2009 The physiological roles of the boar ejaculate. Society of Reproduction and Fertility Supplement 66 1-21. 
Svensson-Arvelund J, Mehta RB, Lindau R, Mirrasekhian E, Rodriguez-Martinez H, Berg G, Lash GE, Jenmalm MC \& Ernerudh J 2015 The human fetal placenta promotes tolerance against the semiallogeneic fetus by inducing regulatory T cells and homeostatic M2 macrophages. Journal of Immunology 194 1534-1544. (doi: 10.4049/jimmunol.1401536)

Verit FF, Verit A, Ciftci H, Erel O \& Celik H 2009 Paraoxonase-1 activity in subfertile men and relationship to sperm parameters. Journal of Andrology 30 183-189. (doi: 10.2164/jandrol.108.004929)

\section{Figure legends}

Figure 1. Control specimens (A-B: human skeletal muscle, C-D: pig liver) for immunolocalization of PON1. In A and C, the samples were pre-incubated with the peptide 
upon which the primary antibody was raised upon (Blocking PON1 peptide ab218259, Abcam) clearly contrasting with the PON1 immunolocalization in the muscle fibers and blood vessels (B), as well as in the hepatocytes/sinusoidal bed (D). Not-counterstained sections, viewed with phase contrast optics. Bar: $50 \mu \mathrm{m}$.

Figure 2. Immunolocalization of paraoxonase type 1 (PON1) in genital organs of boars. Figures 2A-C show sections of the caput (A), corpus (B) and cauda (C) of the ductus epididymides with a noticeably more evident immunostaining in the caput and corpus regions where the principal epithelial cells (arrows) and the surrounding smooth muscle (m) appeared stained (lp: lamina propria, arrow: luminal spermatozoa). Figure 2D depicts a representative section of boar testis, showing most immunostaining was restricted to the interstitial (Leydig) cells (thick arrows), blood vessels and only scattered to spermatogonia (short arrows) and elongated spermatids (long arrow). Figures 2E-G depict accessory sexual glands secretory epithelia of the prostate (2E), the seminal vesicles (2F) and the bulbo-urethral gland (2G). In 2E, note the cytoplasmic location in the prostate (thick arrows), against the membranous (basal and apical, thin arrows) presence in the seminal vesicle (2F) and bulbourethral gland (2G) (Lu: lumen, Lp: lamina propria). Not-counterstained sections, viewed with phase contrast optics. Bar: $50 \mu \mathrm{m}$.

Figure 3. Western blot detection of paraoxonase type 1 (PON1) in genital organs of the boar. L1: protein ladder; L2: pig liver, as positive control; L3: testis; L4: caput of the epdidymis; L5: corpus of the epididymis; L6: cauda of the epdidymis; L7: seminal vesicle; L8: prostate; L9: bulbourethral gland. 
Figure 4. Box-whisker plot showing variation in the paraoxonase type 1 (PON1) activity (Figure 4A) and high density lipoprotein-cholesterol (HDL-C) concentration (Figure 4B) in epididymal fluid and the seminal plasma from the first $10 \mathrm{~mL}$ of spermatozoa-rich ejaculate fraction (SRF, sperm-peak portion), the rest of SRF, the post-SRF and a recomposed entire ejaculate collected from 30 boars (3 ejaculates per boar). Boxes enclose the 25th and 75th percentiles; the line is the median; and the whiskers extend to the 5th and 95th percentiles. (a-e) indicate significant differences $(\mathrm{P}<0.01)$ among samples. 


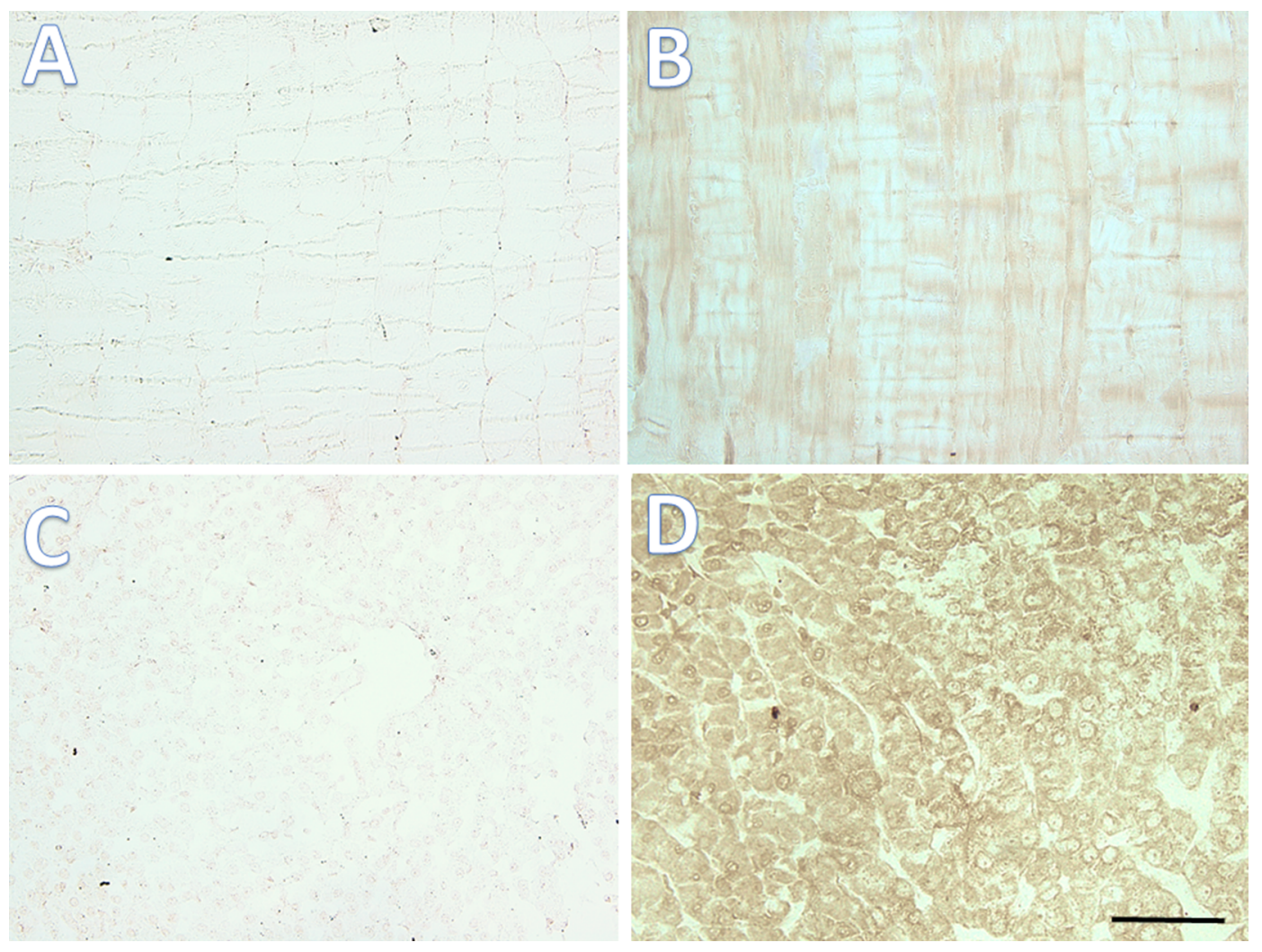




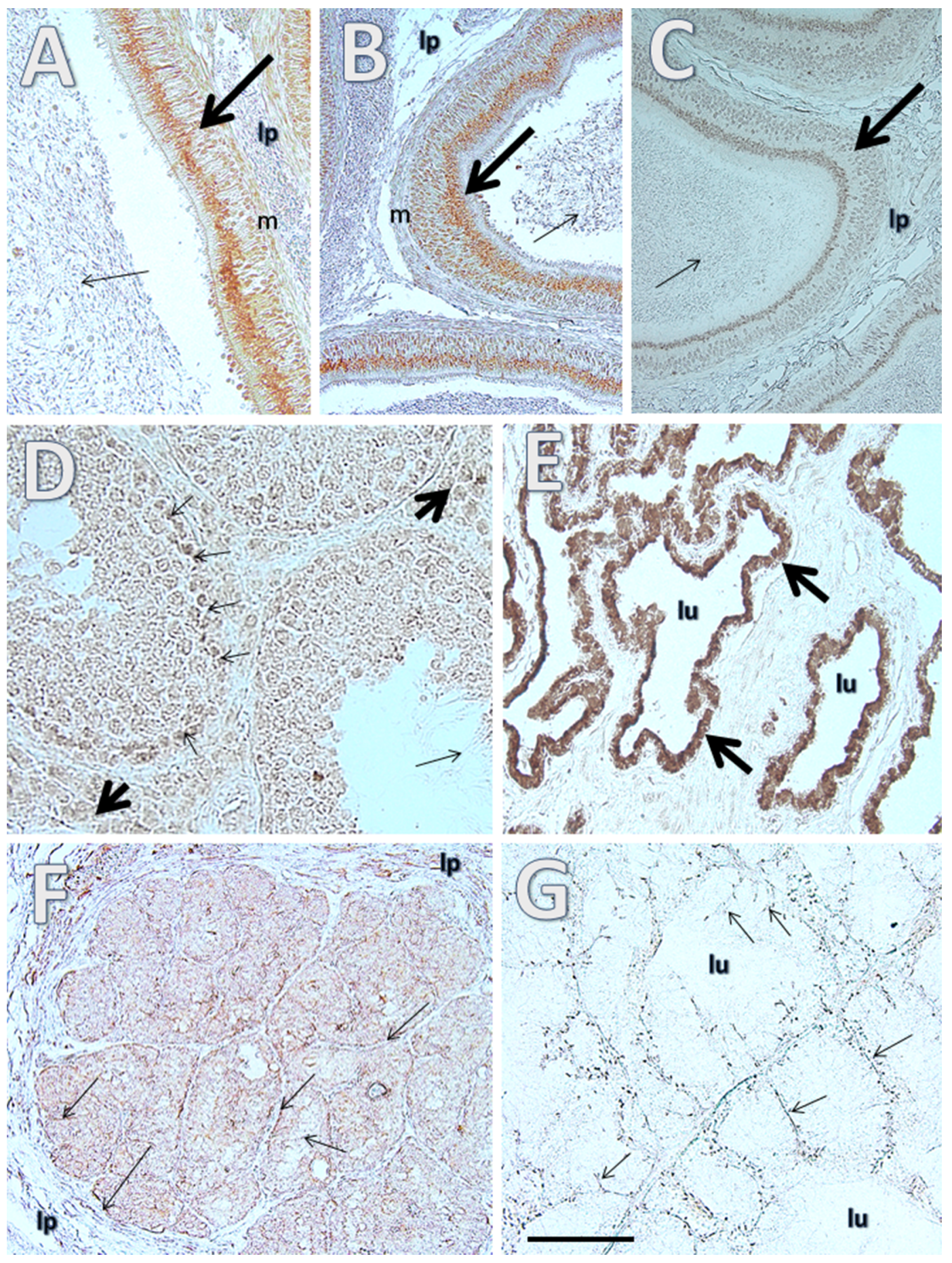




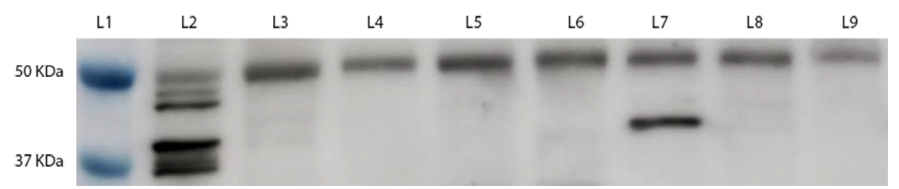



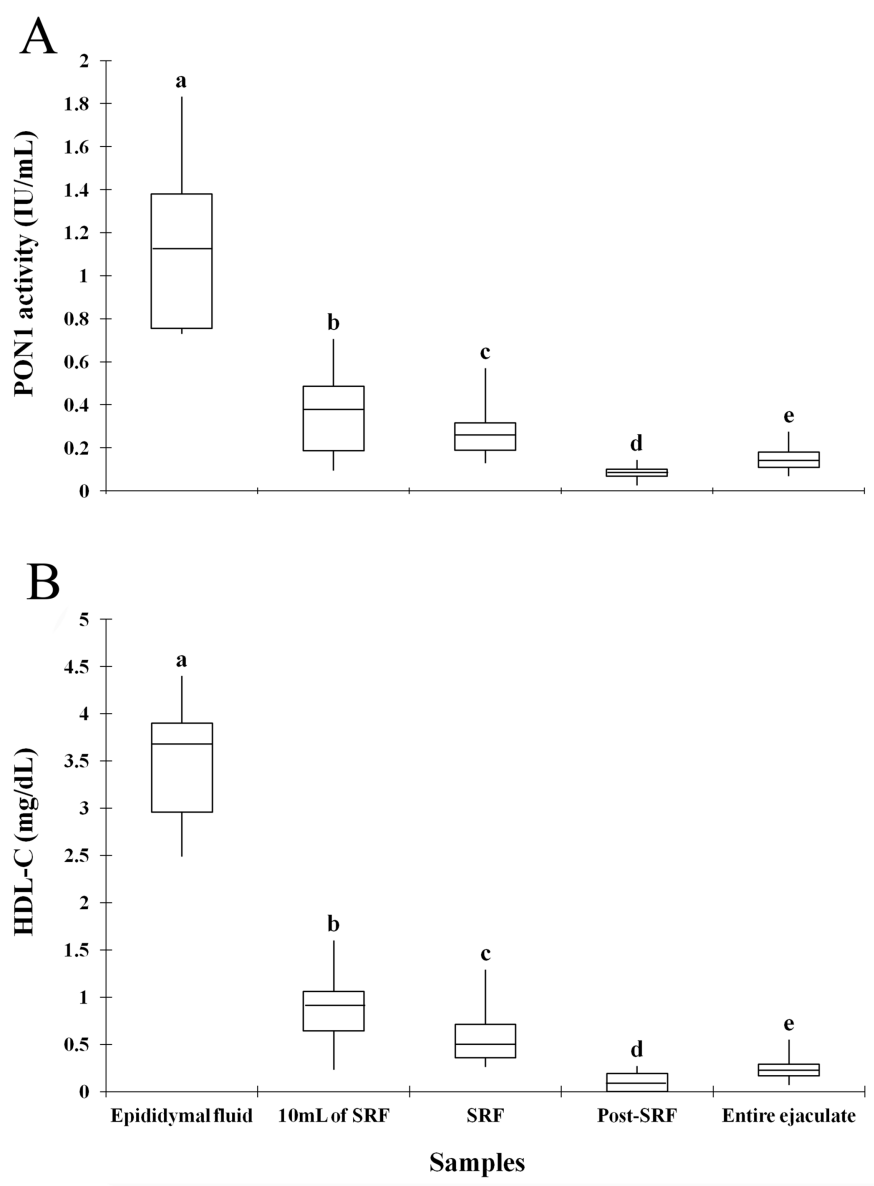